\title{
STAKEHOLDERS PRESENTES NAS MISSÕES ORGANIZACIONAIS: UMA ANÁLISE POR SETOR E ORIGEM DE CONTROLE ACIONÁRIO
}

\author{
Data de submissão: 16/11/2014 \\ Aceite: $15 / 08 / 2016$ \\ Leonardo Fabris Lugoboni 1 \\ Melissa Midori Martinho Goto ${ }^{2}$
}

\section{RESUMO}

O estudo objetivou identificar: a) os stakeholders presentes de forma explícita/declarada nas Missões empresariais; b) a ênfase de determinados Stakeholders considerando o setor de atuação empresarial; c) a ênfase em determinados Stakeholders quando se considera a origem do controle acionário. Para isso, apoiou-se na Teoria e Gestão de Stakeholders e Estratégia Empresarial, por meio de um estudo documental, analisou-se a missão organizacional de $500 \mathrm{em}$ presas brasileiras. Os achados da pesquisa apontam: i) que é importante considerar e analisar stakeholders levando em conta o setor empresarial em que se encontram e ii) que a origem do controle acionário parece ser um elemento a se considerar na política e gestão dos stakeholders.

Palavras-chave: Stakeholders; Missão organizacional; Controle acionário; Setor.

\footnotetext{
1 Possui graduação em Administração de Empresas pelo Centro Universitário Fundação Santo André, CUFSA, mestrado em Administração pela Universidade Municipal de São Caetano do Sul, USCS e doutorado em Administração pela Faculdade de Economia, Administração e Contabilidade - USP, FEAC/USP. Santo André - SP. Brasil E-mail: leo_fabris@hotmail.com.

2 Melissa Midori Martinho Goto

Possui graduação em Administração pela Universidade Federal de Santa Catarina, UFSC e mestrado em Administração pela Universidade de São Paulo, USP. São Paulo - SP. Brasil E-mail: melissamgoto@gmail.com.
} 


\section{INTRODUÇÃO}

A preocupação com a estratégia é antiga e diversas áreas do conhecimento buscaram abordar o assunto. Autores da década de 1930 (COASE, 1937) já defendiam que os objetivos das empresas estão diretamente ligados à gestão financeira (Teoria da Firma) e, na década de 1980, surge a teoria dos Stakeholders que defende que o objetivo das empresas está relacionado a atender as necessidades das diversas partes interessadas sendo que uma das obras mais marcantes é a de Freeman (1984).

Dentro deste contexto, a dicotomia entre Teoria da Firma e Teoria dos Stakeholders intriga diversos autores como Freeman e Reed (1983); Aupperle, Carroll e Hatfield (1985); Griffin e Mahon (1997) e Boaventura et. al. (2009).

Para muitos autores, a missão torna-se a base sobre a qual outras ações são construídas. Todos os objetivos e estratégias só podem ser delineados, depois de uma declaração de missão ter sido desenvolvida (DAVID, 1989; KLEMM; LUFFMAN; SANDERSON, 1991; IRELAND; HITT, 1992; BART, 1997a, e BARTKUS; GLASSMAN; MCAFEE, 2000).

As declarações de missão podem ajudar a focar a organização naquilo que realmente é importante, bem como integrar suas partes interessadas e objetivos financeiros (IRELAND; HITT, 1992) e, portanto, pode-se inferir que uma boa missão pode ajudar as empresas a atingir melhores resultados.

Diversos estudos buscaram descrever a estrutura da missão organizacional, como: Baetz e Bart (1996 e 1998); Silva, Ferreira Jr. e Castro (2006); James e Huisman (2009); Forte e Pereira (2010); Mussoi, Lunkes e Silva (2011); King, Case e Premo, (2011 e 2012), e Lugoboni et al. (2013). E embora seja possível identificar trabalhos tratando da presença dos stakeholders na estrutura da missão organizacional (STRONG, 1997; OMRAN; ATRILL; POINTON, 2002; BARTKUS; GLASSMAN, 2008 e VAN NIMWEGEN et al. 2008) até este momento, não foi possível identificar trabalhos na literatura brasileira tratando dessa temática em específico dentro da literatura sobre stakeholder.

Portanto, com base nessa observação, esta pesquisa busca responder ao seguinte questionamento: Como se modificam os stakeholders presentes na missão organizacional das empresas brasileiras?

Como objetivos de pesquisa tem-se:

Identificar os Stakeholders presentes de forma explícita/declarada nas Missões empresariais.

Identificar se há ênfase de determinados Stakeholders quando se considera o setor de atuação empresarial.

Explorar se há ênfase em determinados Stakeholders quando se leva em consideração a origem do controle acionário empresarial.

Espera-se que, com a identificação dos stakeholders considerados explícitos/declarados, e analisando-os com relação ao setor de atuação e origem do controle acionário, os gestores possam comparar e reformular suas missões e consequentemente sua estratégia empresarial.

A estrutura desta pesquisa é composta por: introdução; conceitos de stakeholders; a relação dos stakeholders e a estratégia; a relação do setor empresarial e da origem do controle acionário com os stakeholders; a missão organizacional e sua estrutura; a missão organizacional e os stakeholders; procedimentos metodológicos; análise dos dados e considerações finais. 


\section{REFERENCIAL TEÓRICO}

\subsection{Stakeholders}

As corporações são pressionadas por um crescente de forças, em que muitas dessas, não raras vezes, não estão sob o controle da corporação. A esse conjunto de forças nomeiase Stakeholders que seriam todos aqueles grupos, partes, atores, requerentes e instituições interessadas - tanto internas à organização como externas - que exercem influência sobre ela.

De forma mais refinada, seriam então os stakeholders todas aquelas partes que afetam ou são afetadas pelas ações das corporações, comportamento e políticas: "[...] stakeholders are all those parties who either affect or who are affected by a corporation's actions, behavior, and policies" (MITROFF, 1983 p. 4).

Assim, stakeholders abrangem um grupo muito maior do que a classe limitada de requerentes/interessados que é conhecido como stockholders, ou acionistas.

Dessa forma, considera-se que stockholders são apenas um dos muitos e diversos grupos que têm impacto sobre as empresas, e que o interesse dos stakeholders, cada vez mais, deve ser considerado pelos stockholders, se quiserem sobreviver (MITROFF, 1983).

Assim sendo, o conceito de stakeholder empregado expande o conceito em relação à constituição fundamental e operação de sistemas que envolver os stockholders, a empresa e os clientes e abarca outros requerentes, instituições, atores, partes e grupos interessados.

De forma ilustrativa, passa-se do mapa tradicional da Figura 1 (Milton Friedman - visão econômica tradicional) para o mapa expandido de stakeholder na Figura 2. Nota-se que os stakeholders estão descritos a partir de uma situação específica no caso a "Drug Company" e a questão dos medicamentos genéricos.

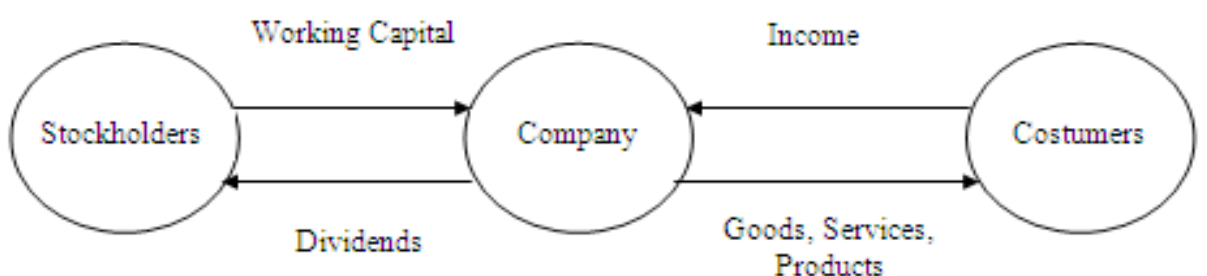

Figura 1. Mapa Tradicional de Stakeholder Fonte: MITROFF, (1983, p. 20)

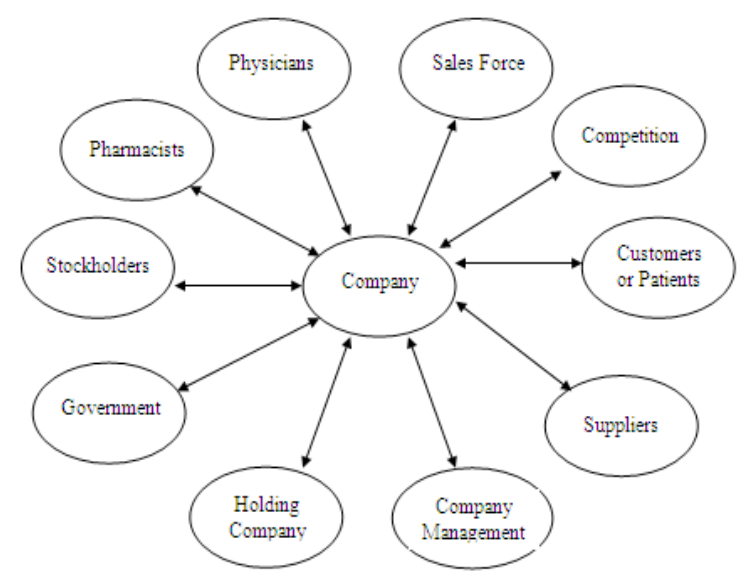

Figura 2. Mapa Expandido de Stakeholder Fonte: MITROFF, (1983, p. 21) 
A figura 2 representa a visão de Mitroff da diversidade de stakeholders, assim como cada um deles afeta e é afetado pela organização.

\subsection{Abordagem de Stakeholders para a Gestão Estratégica}

O uso do termo stakeholders surgiu do trabalho pioneiro no Stanford Research Institute (SRI) na década de 1960 que foi fortemente influenciado pelos conceitos desenvolvidos no departamento de planejamento da Lockheed (FREEMAN; McVEA, 2001).

O trabalho desenvolvido (SRI) argumenta sobre a necessidade de compreensão das preocupações dos acionistas, funcionários, clientes, fornecedores, credores e sociedade, a fim de desenvolver objetivos que os stakeholders apoiassem, e que este apoio era necessário para o sucesso a longo prazo (FREEMAN; McVEA, 2001).

Autores como Dill (1975), Mitroff e Emshoff (1979), Newman (1979), Taylor e Sparkes (1977), Wommack (1979, apud HARRISON, BOSSE, PHILLIPS, 2009), Teixeira e Moraes (2013) e Macêdo, Gadelha e Cândido (2014) incorporaram a perspectiva de stakeholder em suas estratégias de modelo gerencial e ideias, e o denominador comum nesses trabalhos é o argumento de que para atingir alta performance as empresas devem adotar uma ampla perspectiva estratégica que incorpore as necessidades e demandas de múltiplos grupos de stakeholders.

Assim, a abordagem de stakeholder para a estratégia surgiu em meados da década de 1980. Um ponto focal neste movimento foi a publicação de Strategic Management: A Stakeholder Approach de R. Edward Freeman, em 1984, que teve por base os trabalhos de lan Mitroff e Richard Mason, e James Emshoff (FREEMAN; McVEA, 2001). É possível observar esta similaridade comparando a figura 2 (MITROFF, 1983, p. 21) e a figura 3 (FREEMAN, 1984, p.55).

O ímpeto por trás da gestão de stakeholders foi tentar construir uma estrutura sensível às preocupações dos gestores que estavam sendo pressionados por níveis sem precedentes de turbulência ambiental e mudança.

Segundo Freeman (1984), as estruturas de estratégia tradicionais não ajudam os gerentes a desenvolver novas direções estratégicas nem os ajuda a entender como criar novas oportunidades em meio a tantas mudanças. Como Freeman observou: "[...] nossas teorias atuais são incompatíveis com a quantidade e os tipos de mudança que estão ocorrendo no ambiente de negócios da década de 1980" (FREEMAN, 1984, pg. 5). "É necessário uma nova estrutura conceitual" (FREEMAN, 1984, pg. 5).

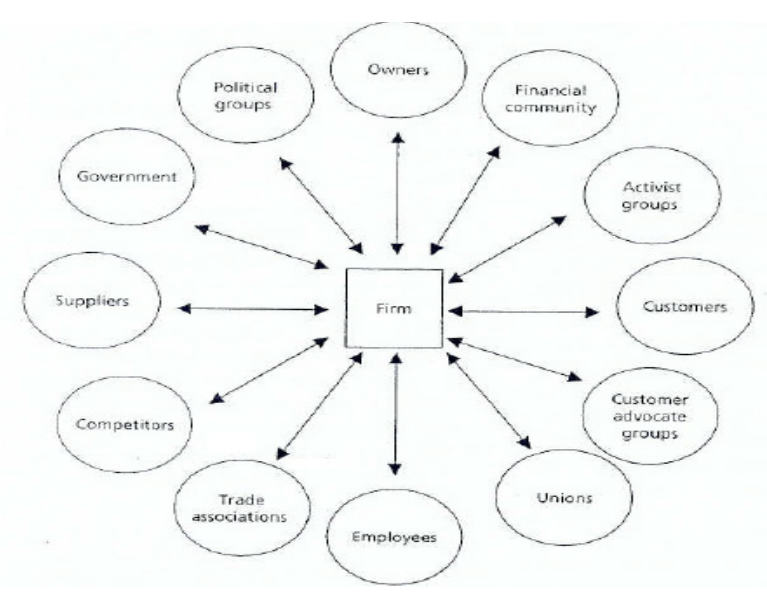

Figura 3. Mapa de Stakeholder de uma grande organização em torno de uma questão estratégica. Fonte: FREEMAN, (1984, p.55) 
A abordagem de stakeholder foi uma resposta a este desafio procurando ampliar o conceito de gestão estratégica além de suas raízes econômicas tradicionais, por meio da definição de stakeholders como qualquer grupo ou indivíduo que é afetado por ou pode afetar a realização dos objetivos de uma organização (FREEMAN, 1984, p. 46). Assim, o objetivo da gestão de stakeholders é o de elaborar métodos para gerenciar os inumeráveis grupos e relacionamentos que resultaram de um modelo estratégico (FREEMAN; McVEA, 2001).

\subsubsection{O Setor empresarial e os stakeholders}

Dentro da literatura de estratégia empresarial, principalmente no trabalho de Porter (1989) em relação às cinco forças da indústria, fica latente a preocupação em se analisar o setor em que a corporação está inserida com a finalidade de se desenvolver uma estratégia empresarial eficiente. Dito de outra forma, parte-se do princípio que as organizações são acometidas por diferentes forças, e que estas variam dependendo do seu setor de atuação.

Nesse sentido, observa-se na literatura de stakeholder que os trabalhos procuram estudar o tema stakeholders sob diferentes propósitos, tendo como unidade de análise setores conforme o Quadro 1.

\section{Quadro 1 - Trabalhos sobre Stakeholder com Unidade de Análise Setor}

\begin{tabular}{|c|c|}
\hline Boaventura; Fischmann (2007) & $\begin{array}{c}\text { Um método para cenários empregando stakeholder analysis: } \\
\text { um estudo no setor de automação comercial }\end{array}$ \\
\hline $\begin{array}{c}\text { Hoffmann, Procopiak Filho; Rossetto } \\
\text { (2008) }\end{array}$ & $\begin{array}{c}\text { As estratégias de influência dos stakeholders nas organizações } \\
\text { da indústria da construção civil: setor de edificações em Bal- } \\
\text { neário Camboriú - SC }\end{array}$ \\
\hline Martins et al. (2009) & $\begin{array}{c}\text { Um estudo das tendências e incertezas do setor de transpor- } \\
\text { tes rodoviários de cargas no Brasil por meio da stakeholder } \\
\text { analysis }\end{array}$ \\
\hline Casagrande; Oliveira; Neves Jr. (2012) & Os stakeholders e seu grau de influência no setor ferroviário \\
\hline Boaventura et al. (2013) & $\begin{array}{c}\text { Priorização de Stakeholders: A relação com a indústria } \\
\text { Bandieira et al. (2013) }\end{array}$ \\
\hline $\begin{array}{c}\text { Saliência de Stakeholders e sua relação com Setor Econômico: } \\
\text { Um Estudo em Empresas Brasileiras de Capital Aberto }\end{array}$ \\
\hline
\end{tabular}

Fonte: Elaborado pelos autores

Ainda que esses trabalhos tenham finalidades diferentes dentro do tema stakeholder, a escolha da unidade de análise por setor, em específico, deixa indícios de que quando se aborda stakeholders a questão do setor a que pertence a corporação parece ter relevância.

Desse modo, com exceção do trabalho Boaventura et al. (2013) que traz a questão de dominância (capacidade dos stakeholders serem remunerados) e a relação dessa com quatro setores (Energia Elétrica - distribuição; Energia Elétrica - transmissão; Financeiro e Seguro; e Aço e Metal) e do trabalho de Bandieira et al. (2013), cujo objetivo foi verificar uma possível associação entre a Indústria e a Saliência de Stakeholders percebida pelos gestores, observa-se que trabalhos vêm sendo desenvolvidos na área de stakeholder levando-se, via de regra, em conta um único setor de análise, havendo espaço no que se refere à uma análise de stakeholders em um amplo campo de setor de atuação empresarial. 


\subsubsection{A origem do controle acionário e a gestão dos stakeholders}

Ainda dentro do contexto de stakeholder, um outro aspecto relevante diz respeito à questão da origem do controle acionário. Friedman e Miles (2006) apontam que pode se esperar diferentes abordagens para a gestão de stakeholders em diferentes culturas ou sociedades. "One would expect different approaches to stakeholder management in different cultures or societies" (FRIEDMAN; MILES, 2006, p. 185).

Segundo os autores, as organizações Anglo-Americanas tendem a buscar o lucro, e a gestão de stakeholders é uma questão voluntária. Em contraposição, citam que em outras regiões é possível que haja uma menor importância na maximização dos retornos para os shareholders.

[...] As empresas Europeia/Japonesa são vistas como uma instituição com personalidade e aspirações. Seus objetivos abrangem uma ampla gama de interessados, mas não pode ser equiparado a qualquer um deles. São percebidas como instituições sociais, com responsabilidades públicas e de interesse público definindo a maneira pela qual são governadas e geridas. Em contrapartida as empresas Anglo-Americanas são vistas como entidade privadas, ao invés de um organismo público, regido pela relação de agente-principal em que os acionistas contratar executivos para dirigi-las. (FRIEDMAN; MILES, 2006, p. 185; tradução livre).

Dessa forma, parece haver uma pré-disposição das empresas Anglo-Americanas a privilegiarem mais os shareholders do que os demais stakeholders, enquanto as empresas Europeias/ Asiáticas tendem a não supervalorizar o shareholder.

Somado a isso, dentro da área de estratégia, é de conhecimento que a influência da origem do controle acionário das empresas determina o modelo de gestão e as políticas da organização (BRAGA et al., 2011).

Disso decorre que pode haver uma reorganização de stakeholders não só em função do setor de atuação que a empresa está inserida, mas também, devido à origem do controle acionário da mesma.

\subsection{A abordagem da missão organizacional e sua estrutura}

A missão organizacional trata-se de uma declaração de propósito duradouro que distingue um negócio de outras empresas de seu tipo e identifica o escopo de suas operações (PEARCE, 1982).

Para Pearce (1982), cada empresa deve decidir sua própria abordagem de missão na tentativa de satisfazer sua percebida responsabilidade social. Diferentes abordagens refletem diferenças no posicionamento competitivo, tipo de indústria, países, pressões ambientais e uma série de outros fatores. Em outras palavras, a missão irá refletir tanto fatores situacionais e diferentes prioridades nas reivindicações das partes interessadas da empresa.

Embora Drucker na década de 70 já tenha discutido o quão importante é a missão organizacional, ao longo do tempo diversas definições de missão foram cunhadas, o que leva a confusões no nível teórico e prático (KLEMM; SANDERSON; LUFFMAN, 1991; STRONG, 1997 KHALIFA, 2012).

Essa confusão teórica sobre a definição operacional do termo missão organizacional foi abordada por diversos autores (SIDHU, 2003; KHALIFA, 2012) que apresentam uma lista de definições diferentes para missão organizacional.

Para esta pesquisa, adotou-se como definição de missão organizacional a abordagem de Khalifa (2012), pois se entende que é uma abordagem atual e embasada nos principais estudos sobre o assunto até a publicação de sua pesquisa:

Consequentemente, uma nova definição de missão é proposta como um compromisso 
firme para criar um valor ou resultado significativo em serviço de uma causa justa - uma causa que os membros da organização admirem e estejam dispostos a exercer a sua atenção e energia em sua busca (KHALIFA, 2012, p. 242).

Os primeiros estudos contemplando a estrutura da missão organizacional datam da década de 80 e novamente não há consenso sobre qual estrutura deve-se usar.

Lugoboni et al. (2013) buscaram consolidar os estudos conceituais e empíricos sobre estrutura da missão organizacional e formularam o Quadro 2.

Quadro 2 - Principais estudos sobre missão e aspectos considerados em sua estrutura

\begin{tabular}{|c|c|c|c|c|c|c|c|c|c|c|}
\hline (1) & 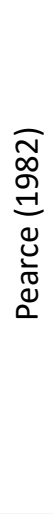 & 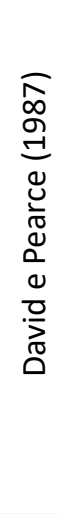 & 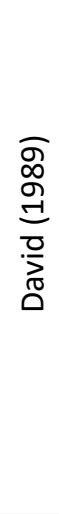 & 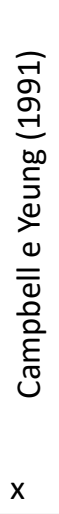 & 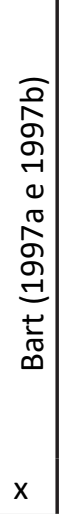 & 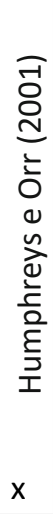 & 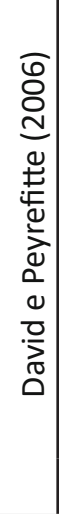 & 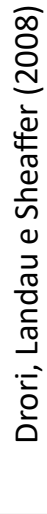 & 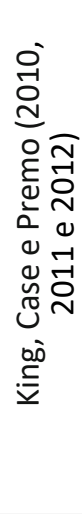 & 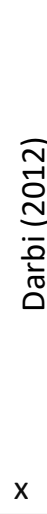 \\
\hline Clientes e mercado alvo & $x$ & $x$ & $\mathrm{x}$ & & $\mathrm{x}$ & $\mathrm{x}$ & $\mathrm{x}$ & $\mathrm{x}$ & $x$ & $x$ \\
\hline Produtos ou serviços oferecidos & $x$ & $x$ & $x$ & & $x$ & $x$ & $x$ & $x$ & $x$ & $x$ \\
\hline Definição do domínio geográfico & $x$ & $x$ & $x$ & & $x$ & $\mathrm{x}$ & $x$ & $x$ & $x$ & $x$ \\
\hline Tecnologias e competências essenciais & $x$ & $x$ & $x$ & & $x$ & $x$ & $\mathrm{x}$ & $x$ & $x$ & $x$ \\
\hline $\begin{array}{c}\text { Compromisso com as metas, sobrevivência, cres- } \\
\text { cimento e lucratividade }\end{array}$ & $x$ & $x$ & $x$ & & $x$ & $x$ & $x$ & $x$ & $x$ & $x$ \\
\hline $\begin{array}{l}\text { Identificação do autoconceito e valores funda- } \\
\text { mentais, filosofia e comportamento da organiza- } \\
\text { ção }\end{array}$ & $x$ & $x$ & $x$ & $x$ & $x$ & $x$ & $x$ & $x$ & $x$ & $x$ \\
\hline Imagem pública desejada. & $x$ & $x$ & $x$ & & $x$ & $x$ & $x$ & & & \\
\hline Acionistas & & & & & $x$ & & & & $\mathrm{x}$ & $x$ \\
\hline Empregados & & & $x$ & $x$ & $x$ & $x$ & $x$ & $x$ & $x$ & $x$ \\
\hline Concorrentes & & & & & & & & & $x$ & \\
\hline Fornecedores & & & & & $x$ & & & $x$ & $x$ & \\
\hline Governo e às leis & & & & & & & & & $x$ & \\
\hline Qualidade & & & & & & $x$ & & $x$ & $x$ & \\
\hline Meio ambiente & & & & & & & & & $x$ & \\
\hline Inovação & & & & & & & & & $x$ & \\
\hline Estratégia competitiva & & & & $x$ & $x$ & & & & & \\
\hline Objetivos não financeiros & & & & & $x$ & & & & & \\
\hline
\end{tabular}

Fonte: LUGOBONI et al. (2013) (grifo nosso)

É possível observar que diversos stakeholders são abordados independentemente do período histórico e do autor que se observa. 


\subsubsection{A missão organizacional, e os stakeholders}

A relação entre os stakeholders e a missão organizacional instigaram diversos autores ao longo do tempo (BARTKUS; GLASSMAN, 2008; JAMES; HUISMAN, 2009; FORTE; PEREIRA, 2010; KING; CASE; PREMO, 2011 e MOIN; ALI; KHAN, 2012).

A precisão das declarações de missão pode ser fundamental para a gestão eficaz dos interesses dos stakeholders e, como consequência, para o sucesso organizacional. Apesar da importância do tema, Bartkus e Glassman (2008), até o ano de 2008, observaram que poucos trabalhos foram realizados sob essa temática.

Para Bartkus e Glassman (2008), a pesquisa empírica indica que as declarações de missão frequentemente incluem stakeholders primários. Baseados no conceito de saliência de Mitchell, Agle e Wood (1997), Bartkus e Glassman (2008) afirmam que nas declarações de missão é possível observar que há evidências de que alguns stakeholders são mais salientes.

Bart (1997), estudando a missão organizacional de 44 empresas industriais, descreve entre seus achados que a identificação das partes interessadas é um dos componentes presentes na missão destas empresas. Outros stakeholders que são abordados de forma direta são os clientes, funcionários e acionistas.

James e Huisman (2009), analisando a missão organizacional de 14 Instituições de ensino superior, observam que algumas instituições usam poucos aspectos, alguns aspectos são muito utilizados, e não havia na sua análise duas instituições exatamente com a mesma configuração de aspectos. A maioria das instituições expressa um compromisso com seus alunos (clientes), pesquisa, bolsa de estudos e compromissos explícitos com país de origem.

Em trabalhos que compararam a missão de empresas pelo mundo, King, Case e Premo (2011) analisaram a estrutura da missão organizacional das 25 maiores empresas nos EUA, Austrália, Canadá e Grã-Bretanha e evidenciaram que "cliente" é o stakeholder mais presente na missão organizacional em cada um desses países. O mesmo resultado foi encontrado pelos mesmos autores King, Case e Premo (2012) quando compararam a missão das 25 maiores empresas dos Estados Unidos, França, Alemanha Japão e China.

Moin, Ali e Khan (2012), analisando a estrutura da missão de 21 bancos privados do Paquistão, evidenciaram que os stakeholders clientes e colaboradores eram alguns dos aspectos mais presentes.

Em trabalhos que observaram empresas brasileiras, Forte e Pereira (2010), analisando a aplicação e estrutura da missão em 17 Instituições de ensino no Ceará, observaram que na missão organizacional dessas empresas a preocupação com stakeholders era comum, principalmente, com o stakeholder cliente.

A definição de padrões é complexa, pois, conforme afirmam King, Case e Premo (2011), as mudanças no ambiente de negócios ocorrem de forma contínua, e é de total relevância acompanhar como as declarações de missões se comportam principalmente ao longo do tempo.

\section{METODOLOGIA}

No que se refere aos objetivos o presente trabalho é classificado como descritivo uma vez que visa descrever as características de determinadas populações ou fenômenos, sendo que uma de suas peculiaridades está na utilização de técnicas padronizadas de coleta de dados. No que se refere aos procedimentos técnicos, a pesquisa pode ser classificada como documental (GIL, 2008).

\subsection{Descrição da Amostra}


O universo de empresas pesquisadas envolveu as 500 empresas listadas no relatório de Melhores e Maiores Empresas Brasileiras do ano de 2012 da Revista Exame. Optou-se por esse universo, pois há evidências de que quanto maior a empresa, maior é sua evidenciação (MURCIA; SANTOS, 2009; MAPURUNGA, et al. 2011 e TRISTÃO; DUTRA, 2012).

Trata-se de um estudo documental em que foi pesquisada na webpage de cada empresa e em seus subdiretórios (institucional, relação com investidores etc.) a declaração de missão organizacional das empresas. No estudo documental são analisados documentos ou informações em que a fonte dos dados ainda não teve um tratamento analítico (SEVERINO, 2007).

Das 500 empresas, 451 tinham a missão disponível na webpage da empresa. Assim, a amostra foi composta de 451 empresas divididas em 20 setores (ver Quadro 3).

Quadro 3 - Setores Analisados e quantidade de empresas

\begin{tabular}{|c|c|c|}
\hline Atacado (34) & Farmacêutico (11) & Serviços (45) \\
\hline Auto indústria (32) & Indústria da Construção (30) & Siderurgia e Metalurgia (25) \\
\hline Bens de Capital (4) & Indústria Digital (11) & Telecomunicações (14) \\
\hline Bens de consumo (42) & Mineração (13) & Têxteis (6) \\
\hline Comunicações (3) & Papel e Celulose (7) & Transporte (15) \\
\hline Eletroeletrônicos (13) & Produção Agropecuária (16) \\
\hline Energia (66) & Química e Petroquímica (29) & \\
\hline
\end{tabular}

Fonte: Elaborado pelos autores

Com relação à origem do controle acionário, existiam 50 empresas da América do Norte; 279 empresas da América do Sul; 13 empresas da Ásia; 88 empresas da Europa e 21 de outros países.

\subsection{Definição Operacional}

Observa-se que na literatura diversos autores procuraram definir quem seriam os Stakeholders o que resulta em uma gama de definições (FRIEDMAN; MILES, 2006).

No entanto, a definição adotada no presente trabalho parte do conceito de Mitroff "[...] all those parties who either affect or who are affected by a corporation's actions, behavior, and policies." (MITROFF, 1983, p. 4) e Freeman "[...] can effect or is affected by the achievements of the organization's objectives"(FREEMAN, 1984, p. 46).

Assim, entende-se por stakeholder as partes que são afetadas pelas ações, comportamento e políticas da empresa e que afetam os objetivos empresariais. Cabe ressaltar que dentro dessa definição estão os stakeholders mais comuns encontrados dentro da literatura sobre o tema que são:

\section{Quadro 4 - Stakeholders, em linhas gerais, mais comuns}

Friedman, Acionistas, clientes, fornecedores e distribuidores, empregados, comunidades locais, Miles, (2006, sindicatos, NGO- ativistas, competidores, governo, financiadores (além de acionistas), P. 13-14) media, aspectos naturais, parceiros de negócio, acadêmicos e gerações futuras.

Mitroff $\quad$ Fornecedores, empregados, clientes e consumidores, aliados (ally), competidores ou (1983, P.35) adversários, reguladores de controle (Governo), e regulações ou controles (matriz-sub- 
Freeman (1984, P. 55)
Acionistas, comunidade financeira, grupos de ativistas, clientes, grupos de defesa do cliente (custumer advocate groups), sindicatos, empregados, associações de comércio competidores, fornecedores, governo e grupos políticos.

Fonte: Elaborado pelos autores

Tendo a definição operacional de stakeholder e as missões das empresas, deu-se prosseguimento à análise dos stakeholders presentes de forma explícita/declarada na missão, ou seja, que estavam presentes sem que fosse necessária uma inferência subjetiva.

Para King, Case e Premo (2010) as declarações de missão são comunicações vitais utilizadas pelas corporações, entre outras funções, para definir quais são suas partes interessadas (stakeholders) e prioridades. Os stakeholders e seus interesses são normalmente abordados nas declarações de missão, visão e valores de uma organização (CURRAN; TOTTEN, 2010).

A seguir exemplos de como foi feita a identificação dos stakeholders presentes nas missões das empresas analisadas. $\mathrm{O}(\mathrm{s})$ stakeholder (s) considerado (s) esta (ao) destacado (s) em negrito.

Promover a evolução social com foco na educação de crianças e jovens de comunidades em desenvolvimento por meio de projetos próprios ou em parceria. Robert Bosch (instituto)

Aumentar o valor para o acionista e para a sociedade e, ao mesmo tempo, reduzir o impacto ambiental. DuPont

Assegurar o fornecimento de cédulas, moedas, selos postais e fiscais, outros meios de pagamento e soluções personalizadas de segurança, atendendo prioritariamente o Estado brasileiro. Casa da Moeda

Observa-se que a identificação dos stakeholders não foi feita utilizando softwares de análise de conteúdo, mas sim lidos um a um, evitando-se assim problemas que poderiam decorrer de termos que poderiam não estar associado à stakeholder (exemplo, "ambiente" que pode ser entendido como ambiente de trabalho e etc.).

Termos similares foram encontrados nas missões analisadas. Dessa forma, recorreu-se ao ajuste de linguagem em que os seguintes ajustes foram feitos:

Equipe; trabalhadores; empregados; funcionários e colaboradores agrupados em "Funcionários"

Comunidade; sociedade; desenvolvimento na região de atuação, agrupados em "Comunidade"

Associados; parceiros; cooperados; franquias, agrupados em "Associados"

Consumidores; clientes, agrupados em "Clientes"

Investidores; acionistas, agrupados em "Acionistas"

Quanto ao termo explicitados/declarados, entende-se que são aqueles stakeholders cuja identificação, a partir da definição de stakeholder adotada, não carece de inferências ou subjetivações extratextuais da missão organizacional das empresas.

A presença ou ausência do stakeholder foi controlada por meio de planilha eletrônica utilizando uma escala dicotômica ( 0 = ausência e $1=$ presença). Os autores avaliaram as missões de forma independente, registrando a presença ou ausência dos stakeholders. As divergências foram discutidas em uma etapa posterior obtendo assim um consenso. 
Para Pearce (1982), a empresa possui partes interessadas "internas" e "externas" e deve identificar e atender às reivindicações das partes interessadas. Segundo o autor, devem ser tomados quatro passos: 1. Identificação dos reclamantes; 2 . Entender de forma específica as demandas; 3 Reconciliação e priorização das reivindicações, e 4. Coordenação de ações com outros elementos da missão. Esses pontos de interesse devem ficar claros uma vez que a missão organizacional possui como um dos principais valores, a definição clara de objetivos organizacionais. (PEARCE, 1982).

Com relação ao Controle acionário, a Fipecafi, entidade responsável pela execução do ranking das melhores empresas do país, define controle acionário como: "É o país de origem do controlador. Multinacionais controladas por holdings constituída no Brasil são classificadas pelo país de origem do controlador final" (FIPECAFI, 2015).

\section{ANÁLISE DOS DADOS}

Ao efetuar-se a análise das missões das 451 empresas, observou-se o seguinte grupo de stakeholders presente (Acionistas; Ambiental; Associados; Clientes; Funcionários; Entidade Pública; Fornecedores, e Comunidade), o que mostrou consonância com principais stakeholders presentes na literatura (FRIEDMAN; MILES, 2006; FREEMAN, 1984; MITROFF, 1983).

Observa-se que nem todas as missões apresentavam stakeholders conforme definido operacionalmente no item 3.2. Assim, das 451 empresas pesquisadas, constatou-se que 337 apresentaram de forma explícita/declarada em sua missão ao menos um stakeholder, e 114 não fizeram menção a nenhum stakeholder, o que de certa forma foge às recomendações de Pearce (1982); David e Pearce (1987); David (1989); Campbell e Yeung (1991); Bart (1997a e 1997b); Humphreys e Orr (2001); David e Peyrefitte (2006); Drori, Landau e Sheaffer (2008); King, Case e Premo (2010, 2011 e 2012); Darbi (2012) conforme Quadro 2 apresentado na sessão 2.3.

\section{Tabela 1 - Presença/Ausência de Stakeholders nas Missões}

\begin{tabular}{|c|c|c|}
\hline Quantidade de Stakeholders & & Freq \\
\hline Apresentam um ou mais Stakeholders & & 337 \\
\hline Não apresentam Stakeholders & & 114 \\
\hline
\end{tabular}

Fonte: Dados da pesquisa

Ao se analisar a presença/ausência de stakeholders na missão empresarial por setor empresarial, contatou-se que determinados setores em sua totalidade, considerando a amostra estudada, explicitam/declaram ao menos um stakeholder em sua missão, que são os setores de Comunicações e Têxtil e que, de um modo geral, todos os setores analisados apresentaram maior porcentagem de empresas declarando/explicitando seus stakeholders na missão do que o contrário. 
Tabela 2 - Presença de Stakeholders na Missão - Análise por Setor

\begin{tabular}{|c|c|c|c|c|c|c|c|c|}
\hline Setor & Sim & Não & Setor & Sim & Não & Setor & Sim & Não \\
\hline Atacado & $84 \%$ & $16 \%$ & Energia & $70 \%$ & $30 \%$ & $\begin{array}{c}\text { Química e Petro- } \\
\text { química }\end{array}$ & $59 \%$ & $41 \%$ \\
\hline Auto indústria & $78 \%$ & $22 \%$ & Farmacêutico & $82 \%$ & $18 \%$ & Serviços & $82 \%$ & $18 \%$ \\
\hline Bens de Capital & $75 \%$ & $25 \%$ & $\begin{array}{l}\text { Indústria da } \\
\text { Construção }\end{array}$ & $77 \%$ & $23 \%$ & $\begin{array}{c}\text { Siderurgia e Meta- } \\
\text { lurgia }\end{array}$ & $72 \%$ & $28 \%$ \\
\hline $\begin{array}{l}\text { Bens de consu- } \\
\text { mo }\end{array}$ & $74 \%$ & $26 \%$ & Indústria Digital & $91 \%$ & $9 \%$ & Telecomunicações & $71 \%$ & $29 \%$ \\
\hline Comunicações & $100 \%$ & $0 \%$ & Mineração & $62 \%$ & $38 \%$ & Têxteis & $100 \%$ & $0 \%$ \\
\hline Eletroeletrônicos & $62 \%$ & $38 \%$ & $\begin{array}{c}\text { Produção Agro- } \\
\text { pecuária }\end{array}$ & $81 \%$ & $19 \%$ & Varejo & $73 \%$ & $27 \%$ \\
\hline Papel e Celulose & $86 \%$ & $14 \%$ & Transporte & $67 \%$ & $33 \%$ & & & \\
\hline
\end{tabular}

Fonte: Dados da pesquisa

Com relação à quantidade de stakeholders, averiguou-se a quantidade de stakeholders que eram citados nas missões, visto que uma missão pode apresentar mais de um stakeholder. Dessa forma, observou-se que a maioria das missões das empresas estudadas apresenta pelo menos um stakeholder. Observa-se que quase 75\% abordam até 2 stakeholders.

Tabela 3 - Quantidade de Stakeholders por Missão

\begin{tabular}{|c|c|c|c|}
\hline Quant. Stakeholder & Freq & \% & \% Acum \\
\hline 0 & 114 & 25,3 & 25,3 \\
\hline 1 & 143 & 31,7 & 57 \\
\hline 2 & 81 & 18,0 & 74,9 \\
\hline 3 & 46 & 10,2 & 85,1 \\
\hline 4 & 35 & 7,8 & 92,9 \\
\hline 5 & 20 & 4,4 & 97,3 \\
\hline 6 & 12 & 2,7 & 100,0 \\
\hline Total & $\mathbf{4 5 1}$ & $\mathbf{1 0 0 , 0}$ & \\
\hline
\end{tabular}

Fonte: Dados da pesquisa 
Por fim buscou-se verificar quais os stakeholders mais presentes considerando as missões de uma forma geral. Assim, teve-se a seguinte classificação em que o stakeholder Cliente aparece como o mais presente, e o stakeholder Entidade Pública é o menos presente nas missões.

Tabela 4 - Stakeholders Presentes nas Missões - Análise por Stakeholder

\begin{tabular}{|c|c|c|c|c|}
\hline Stakeholder & Apresentam & $\%$ & Não Apresentam & $\%$ \\
\hline Clientes & 232 & $51 \%$ & 221 & $49 \%$ \\
\hline Comunidade & 169 & $37 \%$ & 285 & $63 \%$ \\
\hline Funcionários & 102 & $23 \%$ & 351 & $77 \%$ \\
\hline Ambiental & 94 & $21 \%$ & 360 & $79 \%$ \\
\hline Acionistas & 84 & $19 \%$ & 368 & $81 \%$ \\
\hline Associados & 35 & $8 \%$ & 419 & $92 \%$ \\
\hline Fornecedores & 29 & $6 \%$ & 425 & $94 \%$ \\
\hline Entidade Pública & 10 & $2 \%$ & 443 & $98 \%$ \\
\hline
\end{tabular}

Fonte: Dados da Pesquisa

A constatação do cliente como o stakeholder mais presente, corrobora outros estudos empíricos (BART, 1997; JAMES; HUISMAN, 2009; FORTE; PEREIRA, 2010; KING; CASE, PREMO, 2011, e MOIN ALI; KHAN, 2012).

Buscando compreender a presença do stakeholder dentro do setor, as empresas (missões) foram segregadas em setores, e os stakeholders explícitos/declarados foram contabilizados. Essa informação foi relativizada com o total de empresas do setor que possuía ao menos um stakeholder em sua missão organizacional. Observa-se que o total ultrapassa $100 \%$ (linha), pois uma mesma missão poderia conter mais de um stakeholder. Os dados são apresentados na Tabela 5.

De modo geral o stakeholder Clientes é o stakeholder mais explicitado/declarado nas missões organizacionais, o que converge com os achados da Tabela 4, sendo que o setor que é mais expressivo é o de Bens de Capital com presença de $75 \%$ das empresas. No entanto, a Tabela 5 revela algumas nuances, pois apesar de ser o mais abordado de modo geral não é o stakeholder mais abordado nas missões das empresas do setor Comunicações, Energia, Indústria da Construção, Mineração, Papel e Celulose e Serviços.

É possível observar que os stakeholders variam de posição quando se consideram os diferentes setores, o que corrobora com os trabalhos de Porter (1989) sobre a necessidade de se analisar a indústria que uma empresa está inserida para se elaborar a estratégia empresarial, visto haver peculiaridades. 
Tabela 5 - Ranking - Análise por Setor e Stakeholder

\begin{tabular}{|c|c|c|c|c|c|c|c|c|}
\hline Setor/Stakeholder & $\begin{array}{l}\frac{n}{ \pm} \\
. \frac{n}{c} \\
\frac{0}{0} \\
\frac{0}{4}\end{array}$ & 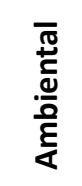 & 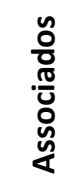 & 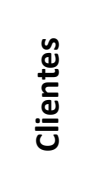 & 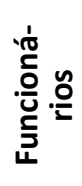 & $\begin{array}{l}\frac{0}{0} \\
\frac{\pi}{0} \\
\text { 음음 } \\
\text { 至 }\end{array}$ & 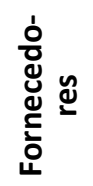 & 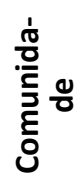 \\
\hline Atacado & $9 \%$ & $28 \%$ & $16 \%$ & $66 \%$ & $19 \%$ & $0 \%$ & $13 \%$ & $38 \%$ \\
\hline Auto indústria & $16 \%$ & $19 \%$ & $0 \%$ & $56 \%$ & $25 \%$ & $0 \%$ & $3 \%$ & $44 \%$ \\
\hline Bens de Capital & $25 \%$ & $25 \%$ & $0 \%$ & $75 \%$ & $25 \%$ & $0 \%$ & $0 \%$ & $25 \%$ \\
\hline Bens de Consumo & $21 \%$ & $12 \%$ & $14 \%$ & $60 \%$ & $19 \%$ & $0 \%$ & $7 \%$ & $29 \%$ \\
\hline Comunicações & $33 \%$ & $0 \%$ & $0 \%$ & $33 \%$ & $33 \%$ & $0 \%$ & $0 \%$ & $67 \%$ \\
\hline Eletroeletrônicos & $15 \%$ & $8 \%$ & $0 \%$ & $54 \%$ & $8 \%$ & $0 \%$ & $0 \%$ & $8 \%$ \\
\hline Energia & $29 \%$ & $32 \%$ & $2 \%$ & $39 \%$ & $21 \%$ & $3 \%$ & $8 \%$ & $56 \%$ \\
\hline Farmacêutico & $9 \%$ & $27 \%$ & $27 \%$ & $64 \%$ & $18 \%$ & $0 \%$ & $0 \%$ & $27 \%$ \\
\hline Indústria da Construção & $13 \%$ & $37 \%$ & $10 \%$ & $37 \%$ & $27 \%$ & $3 \%$ & $0 \%$ & $43 \%$ \\
\hline Indústria Digital & $9 \%$ & $0 \%$ & $0 \%$ & $55 \%$ & $0 \%$ & $18 \%$ & $0 \%$ & $27 \%$ \\
\hline Mineração & $23 \%$ & $23 \%$ & $15 \%$ & $23 \%$ & $15 \%$ & $0 \%$ & $15 \%$ & $38 \%$ \\
\hline Papel e Celulose & $0 \%$ & $57 \%$ & $0 \%$ & $29 \%$ & $0 \%$ & $0 \%$ & $0 \%$ & $43 \%$ \\
\hline Produção Agropecuária & $25 \%$ & $25 \%$ & $38 \%$ & $56 \%$ & $25 \%$ & $0 \%$ & $13 \%$ & $38 \%$ \\
\hline Química e Petroquímica & $21 \%$ & $17 \%$ & $3 \%$ & $45 \%$ & $28 \%$ & $0 \%$ & $0 \%$ & $28 \%$ \\
\hline Serviços & $11 \%$ & $22 \%$ & $9 \%$ & $42 \%$ & $18 \%$ & $9 \%$ & $2 \%$ & $53 \%$ \\
\hline Siderurgia e Metalurgia & $36 \%$ & $24 \%$ & $0 \%$ & $64 \%$ & $44 \%$ & $0 \%$ & $16 \%$ & $40 \%$ \\
\hline Telecomunicações & $14 \%$ & $0 \%$ & $0 \%$ & $71 \%$ & $14 \%$ & $0 \%$ & $0 \%$ & $29 \%$ \\
\hline Têxteis & $17 \%$ & $33 \%$ & $17 \%$ & $67 \%$ & $33 \%$ & $0 \%$ & $17 \%$ & $33 \%$ \\
\hline Transporte & $7 \%$ & $20 \%$ & $0 \%$ & $53 \%$ & $7 \%$ & $0 \%$ & $0 \%$ & $33 \%$ \\
\hline Varejo & $19 \%$ & $0 \%$ & $8 \%$ & $62 \%$ & $41 \%$ & $3 \%$ & $16 \%$ & $11 \%$ \\
\hline
\end{tabular}

Fonte: Dados da Pesquisa

O achado valida também os estudos de Boaventura; Fischmann (2007), Hoffmann, Procopiak Filho; Rossetto (2008), Martins et al. (2009), Casagrande; Oliveira; Neves Jr. (2012), Boaventura et al. (2013) e Bandieira et al. (2013) por terem utilizado, em seus trabalhos sobre stakeholders, a unidade de análise setor e/ou indústria.

No que se refere à influência do controle acionário na presença dos stakeholders, observa-se que quando se consideram dois grupos de origem do controle acionário (América e Europa/Ásia), os resultados divergem do que afirmam Friedman e Miles (2006) quando propõem que as empresas Anglo-Americanas tendem a privilegiar mais os shareholders do que os demais stakeholders quando comparado às empresas Europeias/Asiáticas. Os resultados apontam que as empresas cujo controle está na Europa/Ásia tendem a privilegiar, os Acionistas. As empresas de controle na Europa/Ásia privilegiam o Acionista de forma igual ou um pouco mais que as empresas onde o controle é Anglo-Americano. A mesma divergência ocorre quando Friedman e Miles (2006) afirmam que empresas Europeias/Asiáticas tendem a ter preocupação comunitária maior do que as Anglo-Americanas.

Friedman e Miles (2006) afirmam que as empresas Anglo-Americanas podem focar mais os shareholders uma vez que as empresas Europeias/Asiáticas tendem a possuir mais "personalidade e aspirações". Uma possibilidade para estas divergências pode ser que as missões analisa- 
das foram coletadas nos sítios eletrônicos (quando trata-se das empresas de capital estrangeiro) das filiais, e essas missões podem ter sido afetadas pela mistura cultural brasileira.

Tabela 6 - Ranking - Controle acionário - Análise 1

\begin{tabular}{|c|c|c|c|}
\hline Stakeholder & América & Europa/Ásia & Outros* \\
\hline Acionistas & $12 \%$ & $12 \%$ & $12 \%$ \\
\hline Ambiental & $13 \%$ & $10 \%$ & $7 \%$ \\
\hline Associados & $4 \%$ & $4 \%$ & $8 \%$ \\
\hline Clientes & $29 \%$ & $37 \%$ & $30 \%$ \\
\hline Colaboradores & $13 \%$ & $14 \%$ & $15 \%$ \\
\hline Entidade Pública & $2 \%$ & $1 \%$ & $3 \%$ \\
\hline Fornecedores & $4 \%$ & $2 \%$ & $5 \%$ \\
\hline Comunidade & $23 \%$ & $20 \%$ & $20 \%$ \\
\hline Total & $100 \%$ & $100 \%$ & $100 \%$ \\
\hline
\end{tabular}

* Outros: Anglo-indiano; Bra/Sueco-finland.; Brasilo-australiana; Nipo-Americano; etc. Fonte: Dados da pesquisa

Dando prosseguimento à análise e desmembrando o grupo de ‘Europa/Ásia' em Europa e Ásia, observa-se que as missões das empresas (Tabela 7), cujo controle acionário é Asiático, não apresentam explicitação/declaração do stakeholder Acionista, ao passo que é o quarto stakeholder mais abordado nas missões das empresas com origem de capital Europeu e o quinto stakeholder mais abordado pelas empresas de controle acionário Americano.

Isso decorre no que diz respeito aos Acionistas cujas empresas de origem de controle acionário asiáticos estariam dentro do que foi caracterizado por Friedman e Miles (2006). No entanto, as Europeias não estariam.

No que se refere a ter uma preocupação comunitária maior do que as Anglo-Americanas, as observações de Friedman e Miles (2006) não se confirmam quando se analisam em separado as empresas Asiáticas das Europeias, sendo que as empresas de controle acionário Americanas apresentam um percentual de explicitações do stakeholder Comunidade em suas missões maior do que os outros dois grupos de países, como se pode observar na Tabela 7. Essa divergência novamente pode ser consequência da influência da cultural brasileira, uma vez que as missões não correspondem exatamente às missões das matrizes.

Tabela 7 - Ranking - Controle acionário-Análise 2

\begin{tabular}{|c|c|c|c|c|}
\hline & América & Ásia & Europa & Outros* \\
\hline Acionistas & $12 \%$ & $0 \%$ & $12 \%$ & $12 \%$ \\
\hline Ambiental & $13 \%$ & $11 \%$ & $10 \%$ & $7 \%$ \\
\hline Associados & $4 \%$ & $0 \%$ & $5 \%$ & $8 \%$ \\
\hline Clientes & $29 \%$ & $45 \%$ & $36 \%$ & $30 \%$ \\
\hline Colaboradores & $13 \%$ & $11 \%$ & $14 \%$ & $15 \%$ \\
\hline Entidade Pública & $2 \%$ & $0 \%$ & $1 \%$ & $3 \%$ \\
\hline Fornecedores & $4 \%$ & $0 \%$ & $3 \%$ & $5 \%$ \\
\hline Comunidade & $23 \%$ & $33 \%$ & $19 \%$ & $20 \%$ \\
\hline
\end{tabular}

* Outros: Anglo-indiano; Bra/Sueco-finland.; Brasilo-australiana; Nipo-Americano; etc. Fonte: Dados da pesquisa 
Identificada à situação anterior, e dividindo a América em América do Norte e América do Sul, observa-se (Tabela 8) que as missões das empresas, cujo controle acionário é da América do Sul, explicita/declara mais os stakeholders Clientes, Comunidades, Ambiental e Colaboradores do que o Acionista. E percebe-se uma preocupação maior explicitação do stakeholder Ambiental nas empresas da América do Sul do que na América do Norte.

Observa-se que não se encontrou alinhamento com o que Friedman e Miles (2006) afirmam a respeito das empresas Anglo-Americanas privilegiarem mais determinados stakeholders quando comparado com empresas Europeias/Asiáticas.

Tabela 8 - Controle acionário - Análise 3

\begin{tabular}{|c|c|c|c|c|c|}
\hline & América do Norte & América do Sul & Ásia & Europa & Outros* \\
\hline Acionistas & $14 \%$ & $11 \%$ & $0 \%$ & $12 \%$ & $12 \%$ \\
\hline Ambiental & $8 \%$ & $14 \%$ & $11 \%$ & $10 \%$ & $7 \%$ \\
\hline Associados & $3 \%$ & $5 \%$ & $0 \%$ & $5 \%$ & $8 \%$ \\
\hline Clientes & $41 \%$ & $27 \%$ & $45 \%$ & $36 \%$ & $30 \%$ \\
\hline Colaboradores & $14 \%$ & $13 \%$ & $11 \%$ & $14 \%$ & $15 \%$ \\
\hline Entidade Pública & $0 \%$ & $2 \%$ & $0 \%$ & $1 \%$ & $3 \%$ \\
\hline Fornecedores & $1 \%$ & $4 \%$ & $0 \%$ & $3 \%$ & $5 \%$ \\
\hline Comunidade & $19 \%$ & $24 \%$ & $33 \%$ & $19 \%$ & $20 \%$ \\
\hline
\end{tabular}

* Outros: Anglo-indiano; Bra/Sueco-finland.; Brasilo-australiana; Nipo-Americano; etc.

Fonte: Dados da pesquisa

No entanto, quando se fragmenta esses grandes grupos em grupos de países menores (América do Sul; América no Norte; Europa e Ásia), encontram-se outras configurações, colaborando para a ideia de que a origem do controle acionário das empresas determina o modelo de gestão e as políticas da organização (BRAGA et al., 2011) apontando, então, que a origem do controle acionário é um forte influenciador quando se trata de gestão de stakeholders conforme sinalizado por Friedman e Miles (2006), mas que é necessário analisar os casos separadamente.

\section{CONSIDERAÇÕES FINAIS}

Dada a relação entre a Teoria dos Stakeholders e a estratégia empresarial, sobretudo com a missão organizacional, esta pesquisa buscou responder a seguinte questão: Como varia a estrutura da missão organizacional das empresas brasileiras com relação aos stakeholders abordados?

Evidenciou-se que em empresas brasileiras há diferenças significativas da presença/ausência de stakeholders abordados explicitamente/declarado nas missões organizacionais. Estas variações estão relacionadas às quantidades e quais stakeholders são abordados. Também foi possível observar que é válido e importante analisar os stakeholders levando em conta o setor empresarial a que se relacionam e que o controle acionário parece ser um importante componente na política e gestão dos stakeholders, o que se reflete na missão organizacional.

Embora a presença do stakeholder na missão organizacional não permita compreender como é a gestão dos interesses dos mesmos, a presença dos stakeholders na missão organizacio- 
nal é um forte indício de que a estratégia da empresa os considera de forma significativa e em sua estratégia.

Como contribuição acadêmica desta pesquisa, destaca-se a apresentação da abordagem dos stakeholders nas missões organizacionais das maiores empresas brasileiras. Outra contribuição que merece destaque é a verificação de que os stakeholders apresentados na missão podem sofrer alteração de acordo com o setor de atuação e a origem do seu controle acionário.

Do ponto de vista gerencial, esta pesquisa leva os gestores a refletir sobre suas missões organizacionais, e se seus objetivos estratégicos (principalmente os relacionados aos seus stakeholders) estão claros e como se assemelham/distanciam das empresas do mesmo setor de atuação/controle acionário.

Para estudos futuros, recomenda-se que se realizem estudos qualitativos aprofundados analisando se a presença do stakeholder na missão realmente implica estratégias voltadas a eles, e estudos específicos no que tange à questão do controle acionário da empresa, bem como a origem do controle acionário a que a empresa está submetida. A comparação da missão das matrizes com suas filiais também poderiam ser um forte indício de como a origem do controle acionário pode influenciar na estrutura da missão e nas estratégias relacionadas a stakeholders.

\section{REFERÊNCIAS}

AUPPERLE, K. E.; CARROLL, A. B.; HATFIELD, J. D. An empirical examination of the relationship between corporate social responsibility and profitability. Academy of management Journal, $\mathrm{v}$. 28, n. 2, p. 446-463, 1985.

BAETZ, M. C.; BART, C. K. Developing mission statements which work. Long Range Planning, v. 29, n. 4, p. 526-533, 1996.

.The relationship between mission statements and firm performance: an exploratory study. Journal of Management Studies, v. 35, n. 6, p. 823-853, 1998.

BANDIERA, E. G.; BOAVENTURA, J. M. G; MASCENA, K. M. C.; FISCHMANN, A. A. Saliência de Stakeholders e sua relação com Setor Econômico: Um Estudo em Empresas Brasileiras de Capital Aberto. In: Encontro de Estudos em Estratégia (3Es)., 6., 2013, Bento Gonçalves/RS

BART, C. K. Sex, lies, and mission statements. Business Horizons, v. 40, n. 6, p. 9-18, 1997.

BARTKUS, B., GLASSMAN, M. e BRUCE M. R.. Mission statements: are they smoke and mirrors?. Business Horizons, v. 43, n. 6, p. 23-28, 2000. 
BARTKUS, B. R.; GLASSMAN, M.. Do firms practice what they preach? The relationship between mission statements and stakeholder management. Journal of Business Ethics, v. 83, n. 2, p. 207216, 2008.

BOAVENTURA J. M.; A. A. FISCHMANN. Um método para cenários empregando stakeholder analysis: um estudo no setor de automação comercial. R.Adm., São Paulo, v.42, n.2, p.141-154, abr./maio/jun. 2007.

BOAVENTURA, J. M. G. et al. Teoria dos Stakeholders e Teoria da Firma: um estudo sobre a hierarquização das funções-objetivo em empresas brasileiras. Revista Brasileira de Gestão de Negócios, v. 11, n. 32, p. 289-307, 2009.

BOAVENTURA, J.M.G; BANDEIRA-DE-MELLO, R.; MONZONI, M.P.; SIMONETTI, R.; MASCENA, K.M.C. Stakeholder Prioritization: the industry relationship. In: Strategic Management Society 33rd Annual International Conference, 2013, Atlanta. Proceedings... Atlanta: SMS, 2013.

BRAGA, C.; SANTOS, A.; SILVA, P. P.; NUNES, R. V. A influência da Origem do Controle Acionário no Nível de Disclosure Ambiental no Setor de Energia Elétrica no Brasil. IN: Encontro da ANPAD., 35., 2011, Rio de Janeiro/RJ Anais eletrônicos... Rio de Janeiro. 2011.

CASAGRANDE N. G.; F. P. de OLIVEIRA; O. P. NEVES Jr. Os stakeholders e seu grau de influência no setor ferroviário. Unoesc \& Ciência - ACSA, Joaçaba, v. 3, n. 2, p. 245-260, jul./dez. 2012.

CURRAN, C.R.; TOTTEN, M.K. Mission, Strategy, and Stakeholders. Nursing Economics, Pitman, v. 28, n. 2, p. 116-8, Mar 2010.

COASE, R. H. The nature of the firm. Economica, v. 4, n. 16, p. 386-405, 1937.

DAVID, F. R. How companies define their mission. Long range planning, v. 22, n. 1, p. 90-97, 1989.

FIPECAFI. Critério/Indicadores. Disponível em: http://www.fipecafi.org/downloads/projetoexame-melhores-maiores/mm-criterios-indicadores.pdf>. Acesso em: 16/07/2015. 
FRIEDMAN, A. L.; MILES, S. Stakeholders: Theory and Practice. New York: Oxford University Press, 2006.

FREEMAN, R. E.; MCVEA, J., A Stakeholder Approach to Strategic Management (2001). Darden Business School Working Paper No. 01-02. Available at SSRN: http://ssrn.com/abstract=263511 or http://dx.doi.org/10.2139/ssrn.263511

FREEMAN, R. E.; REED, D. L. Stockholders and Stakeholders: A New Perspective on Corporate Governance. California management review, v. 25, n. 3, p. 88-106. 1983.

FREEMAN, R.E. Strategic management: a stakeholder approach. Boston: Pitman,. 1984.

FORTE, S. H. A. C.; PEREIRA, M. S.. A construção e disseminação da missão nas instituições de ensino superior no Ceará. Revista Gestão e Tecnologia, v. 2, n. 1, p. 1-15. 2010.

GIL, A. C.. Como elaborar projetos de pesquisa. 4. ed. São Paulo: Atlas, 2008.

GRIFFIN, J. J.; MAHON, J. F. The corporate social performance and corporate financial performance debate twenty-five years of incomparable research. Business \& Society, v. 36, n. 1, p. 5-31, 1997.

HARRISON, J.S.; BOSSE, D.A.; PHILLIPS, R.A. Managing for Stakeholders, Stakeholder Utility Functions, and Competitive Advantage. Strategic Management Journal, 31, 58-74, 2010.

HOFFMANN V. E.; PROCOPIAK Filho, J. A.; ROSSETTO, C. R.. As estratégias de influência dos stakeholders nas organizações da indústria da construção civil: setor de edificações em Balneário Camboriú - SC . Ambiente Construído, Porto Alegre, v. 8, n. 3, p. 21-35, jul./out. 2008

IRELAND, R. D. e HITT, M. A. Mission statements: Importance, challenge, and recommendations for development. Business Horizons, v. 35, n. 3, p. 34-42, 1992.

JAMES, H.; HUISMAN, J.. Missions statements in Wales: The impact of markets and policy on congruence between institutions. Journal of Higher Education Policy and Management, v. 31, n. 1, p. 23-35, 2009. 
KHALIFA, A. S.; Mission, purpose, and ambition: redefining the mission statement. Journal of Strategy and Management. Vol. 5 No. 3, pp. 236-251, 2012

KING, D. L.; CASE, C. J.; PREMO, K. M. Current mission statement emphasis: be ethical and go global. Academy of Strategic Management Journal, v. 9, n. 2, p. 71-87, 2010.

A Mission Statement Analysis Comparing the United States and Three Other English Speaking Countries. Academy of Strategic Management Journal, v. 10, p. 21-46, 2011.

. An International Mission Statement Comparsion: United States, France, Germany, Japan, and China. Academy of Strategic Management Journal, v. 11, n. 2, p. 93, 2012.

KLEMM, M., SANDERSON, S. e LUFFMAN, G.. Mission statements: selling corporate values to employees. Long range planning, v. 24, n. 3, p. 73-78, 1991.

LUGOBONI, L. F. et al. A missão organizacional das melhores e maiores empresas do Brasil. In: SEMEAD - Seminários em Administração - FEA-USP., 16., 2014, São Paulo. Anais eletrônicos... São Paulo: Fea-USP, 2014.

MACÊDO, N. M. M. N.; GADELHA, M. A.; CÂNDIDO, G. A. Apresentação da construção dos parâmetros à aplicação do modelo conceitual tridimensional de performance social de Carroll. Revista de Administração da UFSM, v. 7, n. 2, p. 230-248, 2014.

MARTINS, P. et al. Um estudo das tendências e incertezas do setor de transportes rodoviários de cargas no Brasil por meio da stakeholder analysis. Rev. Portuguesa e Brasileira de Gestão, Lisboa, v. 8, n. 1, p. 51-62, 2009.

MAPURUNGA, P. V. R. et al. Determinantes do nível de disclosure de instrumentos financeiros derivativos em firmas brasileiras. Revista Contabilidade \& Finanças, v. 22, n. 57, p. 46-61, 2011.

MITROFF, I. I. Stakeholder of the organizational mind. Jossey-Bass Publishers:São FranciscoWashington-London, 1983. 
MITCHELL, R. K.; AGLE, B. R.; WOOD, D. J. Toward a theory of stakeholder identification and salience: Defining the principle of who and what really counts. Academy of management review, v. 22, n. 4, p. 853-886, 1997.

MOIN, M. F.; ALI, A.; KHAN, A. N.. An Analysis of Mission Statement of Pakistani Commercial (Scheduled) banks using a nine points scale approach of Fred R. David. Interdisciplinary Journal Of Contemporary Research In Business. v. 4, n. 2, Jun. p. 102-120, 2012.

MURCIA, F. D. R.; SANTOS, A.. Fatores determinantes do nível de disclosure voluntário das companhias abertas no Brasil. Revista de Educação e Pesquisa em Contabilidade (REPeC), v. 3, n. 2, p. 72-95, 2009.

MUSSOI, A.; LUNKES, R. J.; DA SILVA, R. V.. Missão institucional: uma análise da efetividade e dos principais elementos presentes nas missões de empresas brasileiras de capital aberto. REGE Revista de Gestão, v. 18, n. 3, p. 361-384, 2011.

OMRAN, M.; ATRILL, P.; POINTON, J.. Shareholders versus stakeholders: corporate mission statements and investor returns. Business Ethics: A European Review, v. 11, n. 4, p. 318-326, 2002.

PEARCE, J.. The company mission as a strategic tool. Sloan Management. V. 23, n. 3, p. 15- 24, 1982.

PORTER, M. E. Estratégia competitiva: técnicas para análise de indústrias e da concorrência. Campus, 1989.

SEVERINO, A. J. Metodologia de trabalho cientifico. 23 Ed. São Paulo: Cortez, 2007.

SILVA, A. J. H; FERREIRA JR, I.; CASTRO, M. Missão organizacional como instrumento para a formulação de estratégias e obtenção de vantagem competitiva: análise comparativa em instituições financeiras brasileiras. Revista de Economia e Administração. V. 5, n. 2. p. 221-242, 2005.

SIDHU, J.. Mission Statements:: Is it Time to Shelve Them?. European Management Journal, v. 21, n. 4, p. 439-446, 2003. 
STRONG, C.. The question we continue to ask: how do organizations define their mission?. Journal of Marketing Practice: Applied Marketing Science, v. 3, n. 4, p. 268-283, 1997.

TEIXEIRA, M. G. C.; MORAES, I. B. O diálogo com stakeholders na teoria e na prática: análise da relação de uma empresa pública do setor industrial com seus stakeholders, para a construção de uma política de responsabilidade social. Revista de Administração da UFSM, v. 6, n. Edição Especial, p. 843-859, 2013.

TRISTÃO, P. A.; DUTRA, V. R. Fatores que influenciam na estrutura de capital das empresas listadas na BOVESPA. Revista de Administração da UFSM, v. 5, n. 2, p. 309-320, 2012.

VAN NIMWEGEN, G. et al. A stakeholder perspective on mission statements: an international empirical study. International Journal of Organizational Analysis, v. 16, n. 1/2, p. 61-82, 2008. 